\title{
Does Women's Proportional Strength Affect their Participation? Governing Local Forests in South Asia
}

\author{
BINA AGARWAL * \\ Institute of Economic Growth, Delhi University, India
}

\begin{abstract}
Summary. - The gender and politics literature has long debated how women's proportional strength affects policy formulation within legislatures. Studies on gender and environmental governance have focused mainly on women's limited participation in local institutions. Both bodies of work leave important aspects unexplored. The former neglects the in-between process - the impact of women's numbers on their effective participation, such as attending and speaking up at meetings, and holding office. The latter neglects to ask: what impact would increasing women's proportions have on participation and what proportions are effective? Rigorous empirical analysis is also scarce. Addressing these gaps, this paper, based on primary data for community forestry institutions in India and Nepal, statistically tests if a group's gender composition affects women's effective participation, and if there are any critical mass effects. The results support the popularly emphasized proportions of one-quarter to one-third, but women's economic class also matters, as do some factors other than women's numbers.
\end{abstract}

(c) 2009 Elsevier Ltd. All rights reserved.

Key words - participation, gender, proportional strength, critical mass, community forestry, South Asia

\section{INTRODUCTION}

\begin{abstract}
Men and women should be equally represented in the executive committee. Then it would make it easier for us to speak, to participate in decision making, and to get decisions implemented in favor of women. The population of male and female is almost equal in our village (Women executive committee members of a community forestry group, Baglung, Nepal, author's survey, 2000-01).
\end{abstract}

More women in legislatures will make a difference because on the women's issues I have dealt with, I had a core of support from women.... Not only will there be more support for bills from women, there will be more male awareness (Woman state legislator in the USA, cited in Thomas, 1994, p. 103).

There is a long standing assertion that women's effectiveness in public forums will depend on their proportional strength in the forum - the greater their presence the greater their ability to influence public policy or political behavior. But how much presence is needed for effectiveness? Many have argued that we need a "threshold representation" (Kymilcka, 1995, p. 147), or a "critical mass." 1 Crossing this threshold, it is argued, will make women's presence effective. ${ }^{2}$ Kanter (1977a,1977b), one of the earliest to broach this issue (without actually using the term critical mass), argues, in the context of industrial corporate functioning, that $15 \%$ would constitute merely a token presence but moving upward would increase effectiveness, with $40-50 \%$ providing a balanced and effective presence. She does not, however, specify any single percentage. Indeed, many writers - most of them focusing on western democratic institutions - support the concept of critical mass without giving figures, and a few mention percentages ranging from 15 to 50 . Thomas (1994), for instance, suggests that for women state legislatures in the USA to influence overall policies, even 25 $30 \%$ is not enough and a figure closer to parity might be needed. Others, also studying US legislatures, suggest $25 \%$ (Carroll \& Taylor, 1989) or 15\% (Saint-Germain, 1989); while Lovenduski (1997, p. 718), from her research on the British House of Commons, argues for $20 \%$, and Bratton and Ray (2002) and Dahlerup (1988) - the former empirically the latter discursively-emphasize $30 \%$ for women in Nordic countries. Rather few, however, statistically verify what proportions make a difference or test for a threshold effect. ${ }^{3}$ Meanwhile, globally, the figure of one-third has gained popularity as the critical mass, and forms the basis for legislating or lobbying for gender quotas in diverse institutions-from parliament to village councils - in most countries. ${ }^{4}$

In these discussions not only is there a scarcity of rigorous statistical testing but also almost all the existing studies concentrate on what a greater female presence may empower women representatives to do (e.g., bring about a policy or legislative change), and virtually none outline the in-between process, namely, how numerical strength might empower women in the process of decision making itself. Active participation (such as attending meetings and speaking up at them) is a necessary intermediate step for women to influence decisions. Studies of western societies, with rare exceptions, implicitly assume that women once inducted into a decision-making body will attend meetings and speak up at them, in greater or lesser degree. In practice, even in the West the presence of more women can help, as the rare studies that have examined this indicate. Thomas (1994), for instance, found that the presence of more women made US female legislators less diffident in expressing themselves. She also noted (1994, p. 89) that having female majorities in a Californian city council and county board of supervisors in the early 1980s had two effects: one,

\footnotetext{
*I am most grateful to Robert Jensen, Paul Seabright, Vikram Dayal, Raghav Gaiha, Sunil Kanwar, Manoj Pandey, and to the journal's anonymous referees for their valuable inputs and comments on this paper. I also thank Manoj Pandey and Ram Ashish Yadav for excellent statistical assistance; the members of my research teams in India and Nepal for their dedicated work in gathering data under difficult field conditions; and several institutions for their local support and hospitality, in particular, AKRSP(I), SARTHI, and VIKSAT (all in Gujarat) and FECOFUN and ICIMOD (both in Nepal). The data used here were collected through a grant from the Ford Foundation (Delhi). I am most grateful to the Foundation for its support. Finally, I thank Gowher Rizvi and the Ash Institute at Harvard University for their hospitality during 2006 when I undertook part of the analysis. Final revision accepted: April 7, 2009.
} 
"the presence of supportive colleagues (other women) encouraged female representatives to speak out and participate in the process rather than exhibit the reticence to which they might otherwise have resorted." Two, the women on the board felt more free to pursue issues which they may not have done otherwise, fearing that their choices would be considered deviant or get little support. This comfort of numbers is likely to be even more important in non-western cultures where rural women, typically unused to public participation, often need the presence of other women to help them overcome restrictive social norms and personal reticence.

This paper empirically examines whether women's proportional strength in the decision-making body of an institution of local governance has an impact on women's effective participation. It also seeks to identify a critical mass effect. Although to date, much of the debate around these issues has been in the context of political institutions at the highest level, it has relevance for a wider range of governance institutions and geographic contexts. In particular, the context of the present study - community forestry institutions in India and Nepalis especially important today, since the conservation of forests (which serve as carbon sinks and can mitigate global warming) can depend on the actions of millions of such groups globally. There has, however, been little empirical testing of how the gender composition of such groups can impact on their functioning, after controlling for the effect of other factors. There is of course a substantial literature on gender and the environment, and a growing body of work on gender and environmental governance. In South Asia, these studies, some focusing on one or two villages or institutions, others on a larger cross-section, point to women's low participation in local institutions of forest governance. ${ }^{5}$ Some authors also discuss, on the basis of field observations, the factors (especially cultural) underlying women's limited presence and voice. These studies, and the insights they provide, as well as my earlier review of these issues in Agarwal $(1997,2000,2001)$ lay the ground for taking the analysis further, especially on two counts. First, we need to go beyond recognizing women's relative exclusion to asking what difference increasing their proportional strength could make; in other words, picking up on the pointers provided by the gender and politics literature. Second, it is time to subject long-standing assumptions and propositions on the difference women can make to more rigorous empirical verification. Most existing studies on local forest governance, when providing statistics (and many provide none), rarely go beyond cross-tabulations. The few studies that, to my knowledge, have sought to statistically test the effect of gender (variously defined) on natural resource management by controlling for other factors, have focused on the impact on project performance, and not on the process of women's participation itself, which is the concern of this paper. ${ }^{6}$ Methodologically, the paper tests the gender effects through regression analysis, while also drawing on qualitative insights from field conversations.

\section{CONTEXT, DATA, AND MEASUREMENT}

The empirical basis for my analysis is primary data collected during $2000-01$ on gendered participation in community forestry institutions (CFIs) in India and Nepal-the two South Asian countries with significant community forestry programs. CFIs are constituted of groups managing forest land owned by the government but given over to local communities/user groups to protect and govern. In India, most of these have emerged under the Joint Forest Management (JFM) Programme launched in 1990, and in Nepal through a somewhat similar initiative in $1993 .{ }^{7}$ In both regions, the CFIs represent a significant shift away from the earlier top-down approach to forest governance to a decentralized approach. In India, CFIs have rights to extract non-timber products and to a proportion of any mature timber that the forest department allows to be harvested. In Nepal, although in principle the CFIs can extract all products and keep the full amount, in practice timber cutting is again restricted according to how the forest department defines "sustainable harvest levels" (Ojha \& Timsina, 2008, p. 216). By the early 2000s (around the time of my survey) India had around 84,000 JFM groups involving 8.4 million households and $22.5 \%$ of its forest land, and Nepal had around 10,000 groups involving about 1 million households and $11.4 \%$ of its forest land. ${ }^{8}$

In both India and Nepal, the CFIs broadly have a two-tier organizational structure, consisting of a general body (GB) with members drawn from the whole village and an executive committee (EC) of 9-15 members. The EC is the core decisionmaking body which, in interaction with the GB (and in varying degree with the forest department), defines the rules for forest use and benefit sharing, the penalties for rule violation, methods of protection, and so on.

Communities, when they begin protecting a forest, restrict the entry of people and animals and use a mix of protection methods, such as employing a guard (usually paid by the community), forming patrol groups, or both, while also keeping an informal lookout for intruders. The forest use rules that CFIs formulate can range from an almost total ban on extraction of forest products to varying degrees of permitted extraction of firewood, fodder, and other products. The rules made can depend on the EC's social and economic composition, forest size and condition, the community's monitoring ability, the nature of the product, and related factors (Agarwal, 2009). Since rural women are the main collectors of non-timber products, in particular firewood, which is rarely purchased, ${ }^{9}$ a strict ban on collection can have negative consequences, especially for the time and energy they must spend in collecting fuel from other sources, and the negative health effects of switching to inferior, smokier fuels such as cropwaste. Women of poor households are the worst affected and have the most stake in the extraction rules, especially for firewood. Since the EC plays a critical role in the running of the CFI and especially in framing extraction rules, the members who constitute the EC have a crucial bearing on how the institution functions, and who gains or loses from it. Notably too, the decisions that EC members make affect both themselves and the larger community, which gives their decisions a much more personalized character than is the case in upper echelons of decision making. It is therefore particularly important to focus on women's proportional strength in the EC and its impact on their effective participation in decision making.

My data relates to 135 CFIs, of which 65 are located in three districts of Gujarat in western India and 70 are located primarily in three districts of Nepal in the middle hills. ${ }^{10}$ The Gujarat districts are Narmada/Bharuch, ${ }^{11}$ Panchmahals, and Sabarkantha. Each district has an important non-governmental organization (NGO) working on community forest management, and all three NGOs have broadly similar aims in terms of participatory development, environmental protection, and social inclusion. Indeed, an important reason for choosing Gujarat was that these three NGOs had information on the gender composition of CFIs. This information was essential for sample selection. No state in India collects comprehensive information of this kind. The government of Nepal, however, does collect such data and this served as the basis of district identification in Nepal (for details, see Agarwal, in press-b). 
The Nepal districts are Baglung, Parbat, and Gorkha, with a small spillover of the sample into Dhading district when replacement CFIs were needed for Gorkha. ${ }^{12}$

Ecologically the Gujarat CFIs fall in a semi-arid zone with dry deciduous forests. The sample population is poor and predominantly tribal and a fair percentage of households migrate seasonally for work. Socially, tribal women are subject to fewer restrictions than Hindu women, although practices such as veiling their faces in public can now be found even among tribal women in some of the study villages, due to upper-caste Hindu influence, proximity to the more conservative state of Rajasthan, and the spread of the socio-religious Bhagat movement with its emphasis (among other things) on female modesty. In Nepal, ecologically, the study districts fall in the middle hills, a sub-tropical zone with mostly deciduous forests, a significant ethnic population, and substantial poverty. The identified districts, however, have relatively low levels of complete landlessness (6-13\% of the households in the districts are landless: GoN, 2001). Socially, there is greater caste/community heterogeneity than in the Gujarat sample, but the study's location in the middle hills makes for less sharp differences in social norms between upper-caste Hindu women and ethnic women than found in the plains, and restrictions on Hindu women have also been declining over time. ${ }^{13}$

The sample CFIs in both Gujarat and Nepal were selected through stratified random sampling from the population of CFIs in each of the identified districts. The main criterion for sample selection was the gender composition of the ECs. In Gujarat, the population of CFIs was stratified into two mutually exclusive categories: ECs with $\leqslant 2$ women and those with $>2$ women in each of the three districts. The two-woman marker stemmed from the fact that including at least two women in the EC is required in Gujarat (as in several other Indian states). Although, in practice, many CFIs fail to adhere to this requirement and some exceed it, this is a relevant criterion since including only two women is a nominal way of following the rule, and including more than two women is a departure from the minimum requirement. In Nepal, including women in ECs is not a requirement, and although guidelines issued from time to time suggest such inclusion (e.g., the 1991 guidelines suggest one-third women), these recommendations are seldom followed. For consistency and easier comparison with Gujarat I therefore used the two-woman marker for selecting Nepal's sample as well, in addition to all-women ECs of which there are a fair number here (unlike their scarceness in Gujarat). ${ }^{14}$ In Nepal the ECs were thus stratified into three mutually exclusive categories: ECs with all-women, ECs with $\leqslant 2$ women and those with $>2$ women (but not all-women). Baglung and Parbat districts were clubbed for sampling due to a limited universe of CFIs with a given gender composition in each, and Gorkha was sampled separately. ${ }^{15}$

For the analysis in this paper, however, I have used only mixed gender ECs since our interest is in the effect of women's proportional strength relative to men and the associated gender dynamics on women's participation. In other words, I have excluded all-women and all-men ECs. ${ }^{16}$ In Gujarat $88 \%$ ( 57 of 65 ) and in Nepal 54\% (38 of 70) of the total sample consisted of mixed gender ECs. In the Gujarat sample the typical EC has 11 members, and about $45 \%$ of the mixed gender ECs have 1-2 women and another $45 \%$ have 3-4 women. Only one has 6 women (the highest number). In Nepal again the typical EC has 11-13 members, wherein about $40 \%$ of the mixed gender ECs have 1-2 women, another 29\% have 3-4 women, and none have more than 7 women. The sample distribution, however, is not representative of the universe, since the sample was purposively selected, given that my interest was not so much in examining why some ECs have few women and others many, but in assessing the effect of having more or fewer EC women on their effective participation. Nevertheless, broadly probing what factors underlay variations in the EC's gender composition, I found a mix of context-specific, nonsystematic factors (historical, leadership-related, the influence of a local NGO staff member, or cultural and demographic aspects) which varied from village to village. For instance, some CFIs with more women on the EC were in regions with a prior history of women's group activity (although unrelated to forestry); other CFIs had forests with substantial potential for producing seasonal products that women collect; yet others had a gender-sensitive NGO staff member who had encouraged women's inclusion, and so on.

A combination of detailed quantitative and qualitative information was obtained using a range of questionnaires, fielded at several levels: the CFI, the village, the household, the individual (key informants), and the forest department. Information was obtained through focused group discussions and semi-structured interviews with EC members, as well as focused group discussions with male and female villagers separately drawn from across the village settlements, and individual interviews with key informants. ${ }^{17}$ The EC provided detailed information on each EC member's sex, age, marital status, caste, land owned, educational level, office held, and whether $\mathrm{s} /$ he had served on the EC before, for the year of the survey, the year of CFI formation, and an in-between year. Written records (where kept by the CFIs) were used for data on meeting attendance by gender. Information on speaking up is based on responses by EC women and men to the question: how many of you spoke up in the last three EC meetings you attended, and grading their answers into "none, some, and most." If half or less of the women EC members said they had spoken up they were categorized under "some" and if over half had done so they were categorized under "most." Women EC members were also asked additional questions about problems encountered in attending or speaking up at meetings. In the focused group discussions with village women, similarly, additional questions were posed on aspects such as firewood shortages and awareness about CFI decisions.

In Gujarat each CFI is linked with a specific village and village-level information was obtained on population characteristics, migration, land ownership, and other aspects. ${ }^{18}$ In Nepal, a CFI can have members from several toles (a tole is between a hamlet and a village in size), and a single forest can have more than one CFI protecting (non-overlapping) parts of it. Here there is no clear set of "village characteristics" that can be identified for the analysis. This difference between Gujarat and Nepal also means that the two regions cannot be clubbed together for analysis without losing information available for Gujarat but not for Nepal. They have thus been analyzed separately. ${ }^{19}$

\section{INDICATORS AND EXTENT OF PARTICIPATION: A STATISTICAL DESCRIPTION}

Participation in decision making is a complex concept. Definitions of participation differ, as do views on whom it is expected to involve, what it is expected to achieve and how it is to be brought about (see Agarwal, 2001 for a detailed discussion). At its narrowest, participation in a group can be defined in terms of nominal membership and at its broadest in terms of a dynamic interactive process in which the disadvantaged have voice and influence in decision making. In other words, participation can have a range of levels. In the 
Table 1. Typology of participation

\begin{tabular}{ll}
\hline Form/level of participation & Characteristic features \\
\hline Nominal participation & Membership in the group \\
Passive participation & Being informed of decisions ex post facto; or attending meetings and listening in on decision making, \\
& without speaking up \\
Consultative participation & Being asked an opinion in specific matters without guarantee of influencing the decisions \\
Activity-specific participation & Being asked to (or volunteering to) undertake specific tasks \\
Active participation & Expressing opinions, whether or not solicited, or taking initiatives of other sorts \\
Interactive (empowering) participation & Having voice and influence in the group's decisions; holding positions as office bearers \\
\hline
\end{tabular}

Note: This is a modified version of the typology presented in Agarwal (2001).

typology given in Table 1, achieving effective participation would involve a shift from the lower to the higher levels. Can women's greater presence in the decision-making body help them move from being nominal members to having effective voice?

My sample contains a sufficient variation in the EC's gender composition for us to test the overall impact of higher female presence on their effective participation, as well as test for critical mass (threshold) effects. I examine three dimensions of effectiveness: attendance at meetings, speaking up at meetings, and holding an official position.

\section{(a) Attendance at meetings}

Information on attendance at meetings, as noted, is based on the recorded minutes of meetings held. Fifty-seven percent of the 57 mixed gender CFIs in Gujarat and 100\% of the 38 mixed gender CFIs in Nepal had records on attendance by gender. This gave me a sample of 303 and 335 meetings for the two regions, respectively. ${ }^{20}$ For both Gujarat and Nepal the analysis covers meetings for all the years the CFI had functioned.

On attendance, two aspects are of particular importance. First, for gender representation there should be at least some female presence in every meeting, namely, there should be as few meetings as possible with no women. The indicator used for this is the percentage of meetings in each CFI that had no women. Second, we would like to capture any critical mass effect. Our argument here is that a lone woman on the EC is less likely to attend than if she has company. We might expect this on the grounds that village women would be better placed to overcome restrictive social norms if there are other women to keep them company, to motivate each other to attend, and to make their presence in the traditionally male space more socially acceptable within the community and family. However, this effect may be greater where ECs have very few women and may decline beyond a point as women feel less compelled to attend if several others are attending anyway.
Capturing a threshold effect is not straightforward since simply increasing women's numbers on the EC will increase the mathematical probability of at least one woman attending a meeting. In other words, even if each woman's likelihood of attending is independent of every other woman's likelihood of attending, simply increasing the overall numbers will lead to more women attending. What we need to test is whether the likelihood of each women attending is dependent on the percentage of women in the group. To test this I have calculated the average proportion of EC women attending a meeting, or what I term the female attendance rate per CFI, as follows: Female attendance rate for CFI $A=\frac{1}{n} \sum_{i=1}^{n} \frac{w_{i}}{w}$, where $w_{i}$ is the number of EC women attending the $i$ th meeting $(i=1,2, \ldots, n) ; w$ is the number of EC women in CFI A; and $n$ is the number of meetings held in CFI A.

As an illustration, if CFI A has 3 women in the EC and holds 4 meetings, each attended by $2,3,1$, and 0 EC women, the female attendance rate in this CFI is $(2 / 3+3 / 3+1 /$ $3+0) \div 4=0.5$. If there is a threshold effect, we would expect this attendance rate to rise as the proportion of women on the EC increases but not in a linear way.

If the attendance rate does not rise, or rises rather little until some critical proportion of EC women is reached and then rises significantly, then we can conclude that there is a threshold effect around that proportion. It could taper off subsequently. In the next section I test this through regression analysis by examining whether the female attendance rate is significantly related to particular percentages of women on the EC. Below I simply describe women's attendance as measured by these two indicators.

In Gujarat, $26 \%$ of the EC meetings had no women attending, while in $16 \%$ of the meetings one-third or more of those attending were women (Table 2). Hence a large percentage of meetings had no female presence and only a small percentage had the popularly emphasized one-third. Women's attendance improved with more women in the EC. For instance, in ECs with $\leqslant 2$ women only about $60 \%$ of the meetings had some women attending, while in ECs with $>2$ women there

Table 2. Gujarat and Nepal: percentage of EC meetings with given percentage of women attending

\begin{tabular}{|c|c|c|c|c|c|c|}
\hline \multirow{3}{*}{$\begin{array}{l}\text { Percent attendees } \\
\text { who are women }\end{array}$} & \multicolumn{3}{|c|}{ Gujarat } & \multicolumn{3}{|c|}{ Nepal } \\
\hline & $\leqslant 2$ EC women (136) & $>2$ EC women (167) & All CFIs (303) & $\leqslant 2$ EC women (139) & $>2$ EC women (196) & All CFIs (335) \\
\hline & \multicolumn{6}{|c|}{$\%$ EC meetings } \\
\hline$>0-<15$ & 25.7 & 16.2 & 20.5 & 38.1 & 17.3 & 26.0 \\
\hline$\geqslant 15-<25$ & 16.9 & 21.6 & 19.5 & 15.1 & 14.3 & 14.6 \\
\hline$\geqslant 25-<33$ & 8.1 & 27.5 & 18.8 & 9.4 & 17.9 & 14.3 \\
\hline
\end{tabular}

Note: Figures in brackets give the number of meetings. 
Table 3. Gujarat and Nepal: Female attendance rate (means)

\begin{tabular}{lcc}
\hline & Gujarat (32) & Nepal (38) \\
\hline CFIs with given number of women in the EC \\
$\leqslant 2$ women & 0.43 & \\
$>2$ women & 0.54 & 0.45 \\
CFIs with given \% of women in the EC & 0.58 \\
$<25 \%$ women & 0.39 & \\
$\geqslant 25-<33 \%$ women & 0.74 & 0.43 \\
$\geqslant 33 \%$ women & 0.42 & 0.56 \\
All CFIs & 0.50 & 0.59 \\
\hline
\end{tabular}

Notes: Figures in brackets give the number of CFIs.

were women in $87 \%$ of the meetings. In contrast, there were no EC meetings where men were entirely absent. In Nepal, women's overall attendance was better than in Gujarat - there was at least one woman in about $82 \%$ of the meetings. But like Gujarat, women's attendance improved as their numbers in the EC increased. For instance, women were present in $94 \%$ of the meetings where the EC had $>2$ women members, but were present in only $64 \%$ of the meetings where the EC had $\leqslant 2$ women.

In both Gujarat and Nepal, the female attendance rate was also notably higher among ECs with more than two women relative to those with two women or less; and much higher for ECs with 25 to $33 \%$ women relative to those with less than $25 \%$ women. After reaching this level, however, it declined substantially in Gujarat and leveled off in Nepal (Table 3). In other words, the highest female attendance rate occurred when there were 3-4 women in a typical EC of 11-13 members.

\section{(b) Speaking up}

The second measure of participation is whether women who attend meetings speak up at them. Speaking up is a more complicated variable than attending meetings, since even if women feel empowered to speak up not all of them will speak. If they agree with the point being made, they may remain silent or simply nod. Yet often village women, unless they have selfconfidence, tend not to speak in male-dominated committees even when they have something to say. Hence the presence of other women may be necessary for even one woman to speak. Given the nature of this variable, it is not possible to identify a potential threshold effect, but we can examine whether the chances of at least one woman speaking up are greater if there are more women in the EC, using the same gender composition intervals as used for women's attendance.

In Gujarat, in a third of the ECs the women reported being completely silent in meetings while men reported that at least some of them had spoken up in all meetings (Table 4). In fact, even in ECs with more than two women, in around a third of them the women had remained silent. The substantial gender gap does suggest that diffidence rather than silent acquiescence is at play. As we will see from the regressions, a substantial presence is needed for Gujarat women to speak up. When asked whether their speaking up had changed any EC decisions, $17 \%$ claimed it had, but again the percentage was twice as high among ECs with more than two women than in those with less than two women (namely, $21 \%$ relative to $10 \%$ : table not given here).

In Nepal, women tend to be somewhat less socially constrained - in about $75 \%$ of the CFIs at least some of them reported speaking up at EC meetings (Table 4). Also in about one-third of the CFIs the women EC members felt they had had an impact on decisions at some point in time or otherthis was again far greater than in Gujarat. In both regions, however, women said that it would be easier for them to speak up if there were more women in the EC. Men, in contrast, tended to voice their views irrespective of the EC's gender composition. In other words, while substantial male presence restricted women's voice substantial female presence did not restrain men. ${ }^{21}$

\section{(c) Office bearing}

A third aspect of participation is holding official positions within the EC, such as those of president, vice-president, secretary/joint-secretary or treasurer/co-treasurer. How frequently do EC women hold such positions? Rarely in Gujarat but commonly in Nepal-only 5\% (3 of 57) of Gujarat's mixed gender CFIs relative to $42 \%$ of Nepal's had female office bearers at the time of the survey. The Gujarat figures indicate that simply having more women on the EC is not a sufficient condition for women to break this glass ceiling. In all three cases where women held office in Gujarat, the local NGO had imparted leadership training. In Nepal, however, where cultural norms are less restrictive, women hold office more commonly, although still much less frequently than men. At the time of my survey, half the male EC members and $13 \%$ of female EC members on average were holding office. But women were typically vice-presidents, joint secretaries, and co-treasurers and rarely presidents, secretaries, or

Table 4. Gujarat and Nepal: speaking up in EC meetings (\% of CFIs)

\begin{tabular}{|c|c|c|c|c|c|c|}
\hline \multirow{3}{*}{$\begin{array}{l}\text { How many spoke up in last } \\
3 \text { EC meetings attended? }\end{array}$} & \multicolumn{3}{|c|}{ Gujarat } & \multicolumn{3}{|c|}{ Nepal } \\
\hline & $\leqslant 2$ EC Women & $>2$ EC Women & $\overline{\text { All CFIs }}$ & $\leqslant 2$ EC Women & $>2$ EC Women & All CFIs \\
\hline & \multicolumn{3}{|c|}{ Female EC members } & \multicolumn{3}{|c|}{ Female EC members } \\
\hline None & 37.5 & 35.0 & 36.1 & 42.9 & 13.0 & 24.3 \\
\hline Some & 50.0 & 35.0 & 41.7 & 57.1 & 34.8 & 43.2 \\
\hline \multirow[t]{2}{*}{ Most } & 12.5 & 30.0 & 22.2 & 0 & 52.2 & 32.4 \\
\hline & $(N=23)$ & $(N=27)$ & $(N=50)$ & $(N=15)$ & $(N=21)$ & $(N=36)$ \\
\hline None & 0 & 0 & 0 & 0 & 0 & 0 \\
\hline Some & 34.8 & 29.6 & 32.0 & 26.7 & 23.8 & 25.0 \\
\hline Most & 65.2 & 70.4 & 68.0 & 73.3 & 76.2 & 75.0 \\
\hline
\end{tabular}

Note: $\mathrm{N}$ is the number of CFIs with information. 
treasurers. In other words, they usually occupied supportive rather than leadership positions.

Below I statistically examine through regression analysis whether women's proportional strength on the EC affects their effective participation, after controlling for the effect of other variables which can also impinge on this.

\section{FACTORS AFFECTING PARTICIPATION: REGRESSION ANALYSIS}

\section{(a) Measurement and hypotheses}

Women's effective participation (the dependent variable) covers three dimensions: attending EC meetings, speaking up at EC meetings, and holding office. For Gujarat, given the very few office bearers, the analysis was confined to three indicators of participation: percentage meetings with no women for all the years that the CFI had functioned, average female attendance rate, and the extent to which women spoke up at meetings. For Nepal, in addition to these three indicators there are two for office bearing - the percentage of current female EC members who are office bearers, and the gender gap in office bearing measured as the difference in the percentage of current male and current female EC members who are office bearers.

Four types of factors could impinge on the prospects of women's participation on all these counts: EC characteristics (including gender composition), CFI characteristics, village/ location characteristics, and special interest characteristics. We are especially interested in the impact of the EC's gender composition. We would expect, for instance, that the greater the proportion of women in the EC the more likely that women will attend meetings, speak up at them, and hold office. At the least we can expect simply a numbers effect. In addition there can be a critical mass effect. I hope to capture any threshold effect through the female attendance rate, by testing how it responds to changes in the percentage of women in the EC. It is unlikely that a single point holds in different contexts so I have divided the proportion of women in the EC into three intervals: CFIs with $<25 \%$ women in the EC; CFIs with $\geqslant 25-<33 \%$ EC women; and CFIs with $\geqslant 33 \%$ EC women. These intervals were selected since a quarter or one-third (and especially the latter) are often treated as markers representing the relevant critical mass. These divisions also worked well for the sample distribution. In Gujarat $95 \%$ of the ECs fall in the $15-50 \%$ women range and there are no mixed gender ECs with over $55 \%$ women. In Nepal $71 \%$ of the ECs fall in the $15-50 \%$ range and there are no mixed gender ECs with over $64 \%$ women.

Although our interest is particularly in the impact of the EC's gender composition, some related gender variables could also affect women's participation, such as whether the EC women are literate, their economic status (e.g., whether they come from landless or landowning households), or the prevalence of problems of special concern to women, such as firewood shortages. Illiteracy could be an obstacle especially to women speaking up and holding office, the former because it reduces women's self-confidence and negatively affects men's attitudes toward women, and the latter because holding office can involve tasks which need literacy. Similarly age can matter: older women face fewer social restrictions on their mobility and on speaking in public and could be better placed to hold office. The woman's economic status could, however, go either way. The landless would tend to be more motivated to attend meetings and speak up at them because they have more at stake, but they might be less able to attend due to time constraints (resulting, say, from job search and wage work demands). The results will show which of these opposing tendencies prevails. The EC's caste composition could also affect women's participation - greater social homogeneity would encourage women to attend meetings and speak up at them, greater heterogeneity is likely to have the opposite effect. In Gujarat there is little caste variation and a dominance of tribal groups ( $88 \%$ of EC members are from tribal communities), but in Nepal there is some caste variation and here the effect of heterogeneity could be examined.

At the CFI level, we would expect women to have a higher effective participation where external agents such as NGOs or the forest department have been involved in its functioning (e.g., in the CFI's initiation or in its rule making), since they would tend to infuse less conservative attitudes than those prevalent in the community traditionally. Another factor that can motivate women to participate is shortages of essential items such as firewood. (A CFI was taken as a site of firewood shortages if discussions with women EC members and village women indicated that the majority of households were facing a shortage.) EC women may attend meetings and speak up at them in order to draw men's attention to the problem. Village women also tend to exert pressure on women EC members to take this matter up within the EC. For speaking up, the method of protection can also matter, especially if guards are employed, since guards tend to be stricter than village patrols, and women often have arguments with guards over firewood theft. These conflicts come up for discussion in EC meetings and require women to respond.

Participation could also depend on when the CFI was formed. In Gujarat, for instance, around the mid-1990s when donor agencies and independent observers pointed to women's low participation in the CFIs, the NGOs began to make special efforts to enhance participation in various ways, such as by taking villagers on "exposure visits" to other CFIs to broaden their approach and holding gender-sensitizing workshops for its field staff. I therefore used 1995 as a marker to see if participation was greater among CFIs formed after that year. In Nepal, 1996 is a marker for office bearing since that was the year when FECOFUN (Federation of Community Forestry Users, Nepal) - a country-wide network of CFIs with elected representatives - was formalized, with a mandate that half of its office bearers should be women, and the effect of this could have percolated down to local CFIs.

In addition, locational/geographic characteristics can affect participation in complex ways. There can be location-specific institutional influences (e.g., the presence of NGOs), social influences (some Gujarat villages have gender-conservative religious movements), ecological variation (although not substantial), and demographic and economic influences, such as migration and inequalities in village land ownership. Villages with higher male out-migration can increase the time constraints on women left behind and so adversely affect their ability to attend EC meetings. Village landlessness can have the same effect but migration is a more direct measure. Inequalities in village landownership - a measure of economic heterogeneity in the village - can also exert pressure on women by creating a conflictual dynamics. In Nepal, locational variables are limited to the CFI districts, the number of toles from which the CFI members are drawn, and the percentage of CFI member households with migrant males. There are no villagelevel variables, however, given the absence, noted above, of a one-to-one relationship between the village and the CFI in Nepal. Also while conceptually we would expect the above variables to affect women's effective participation, in practice 
some are not usable for both regions. For instance, there is rather little caste variability in the Gujarat ECs and little landlessness in the Nepal ECs (only 1\% are landless on average).

Across all the equations our primary interest is the impact of the gender variable which is consistently included in each equation. All the equations also contain those non-gender variables which are conceptually important to test, but there are some small variations between models in relation to additional explanatory variables. Some of the explanatory variables for measuring gender composition are continuous and some binary (dummy variables). The continuous gender variable is simply defined as the percentage of women in the EC. In addition, several gender dummies are used. For attending meetings and office bearing, since the dependent variables are continuous the estimation procedure used is ordinary least squares (OLS) with the standard errors corrected for heteroskedasticity to give robust standard errors. For speaking up, since the dependent variable is binary, logistic analysis is used.

\section{(b) Regression results}

The regression results are summarized in Tables 5 to 9. The variable definitions and descriptive statistics are given in Appendix Tables A1 and A2.

\section{(i) Attending meetings}

The EC's gender composition, as hypothesized, has a significant positive effect on women attending meetings, that is, the more women there are in the EC the lower the percentage of meetings with no women. In both Gujarat and Nepal, the percentage of EC meetings with no women attending is significantly less if ECs have $\geqslant 25-<33 \%$ women (or $\geqslant 33 \%$ women) than if they have $<25 \%$ women. In both regions, there is a 36-point difference in the percentage meetings with no women between ECs with $\geqslant 25-<33 \%$ women and those with $<25 \%$ women (Table 5, Eqn. 1; Table 6, Eqn. 1). Beyond one-third EC women, however, the gain is limited and tapers off. These results provide a strong case for having more women on the EC, given our interest in ensuring at least some female presence at each meeting.

Moreover, the female attendance rate (the average attendance rate for EC women per meeting) helps identify a poten- tial threshold effect. For Gujarat we find that the attendance rate among ECs with $\geqslant 25-<33 \%$ women is significantly higher by 0.35 relative to ECs with $<25 \%$ women, and significantly higher by 0.28 relative to ECs with $\geqslant 33 \%$ women. In other words EC's with women within the proportions of $\geqslant 25$ $<33 \%$ have a significantly higher female attendance rate than ECs outside these proportions. Beyond 33\% there is a dropping off. Either this is because some women assume others will attend anyway as the number of women increases from 3 to 4 5 in a typical 11 member EC (but there is no qualitative evidence to suggest this), or the effect is not showing up after $33 \%$, given the rather few CFIs with more than 33\% EC women with gender information on attendance. Nepal's results, however, give a clear threshold effect. The attendance rate is higher by 0.23 among ECs with $\geqslant 25-<33 \%$ women compared to ECs with $<25 \%$ women. Beyond $33 \%$ although the rate is still significantly greater than with $<25 \%$ women it is not significantly different from ECs with $\geqslant 25-<33 \%$ women. In other words the rate tapers off after $33 \%$. Interestingly, in both Gujarat and Nepal, the critical mass figures-25-33\%-are in line with those that are popularly afloat, underlining the importance of having at least one-quarter to one-third women in decision-making bodies.

The comfort of numbers in increasing attendance is also emphasized by women themselves. During focused group discussions women often mentioned that having more women in the EC would help them both attend EC meetings and speak up at them. Some sample responses are given below:

If more women attend, if the tradition in the village changes then we can go to EC meetings regularly (EC women in Panchmahals district, Gujarat, author's survey, 2000-01)

If there were more women in the Mandali [CFI] it would be good. That would encourage women to attend meetings and speak up (EC women in Narmada district, Gujarat, author's survey, 2000-01).

Factors other than the EC's gender composition, such as landownership (or its lack) among EC members, the EC's average age, gender-friendly external agents, and CFI location, impinge on meeting attendance and attendance rates as well. For instance, women are found more likely to attend meetings both where there is a higher percentage of landless women in the EC and where there is an overall higher average

Table 5. Gujarat: factors affecting women's attendance in EC meetings

\begin{tabular}{lcc}
\hline & \multicolumn{2}{c}{ Dependent variables } \\
\cline { 2 - 3 } & Percent meetings with no EC women & Female attendance rate $\Omega$ \\
\hline Statistical method & OLS (r) & OLS (r) \\
Equation no. & $(1)$ & 32 \\
No. of observations & 32 & 0.64 \\
$R^{2}$ & Coef. & 0.62 \\
Explanatory variables & $-35.96^{* * *}(0.004)$ & $0.35^{* * *}(0.001)$ \\
\hline GenComp3: Dummy ( $\geqslant 25-<33 \%$ EC women $=1)$ & $-20.00^{\dagger}(0.102)$ & $0.07(0.512)$ \\
GenComp4: Dummy ( $\geqslant 33 \%$ EC women $=1)$ & $-21.88^{* *}(0.015)$ & $0.24^{* * *}(0.000)$ \\
Average land owned by all EC members (ha) & $-0.12(0.413)$ & $0.003^{*}(0.052)$ \\
\% EC women from landless households & $31.73^{* * *}(0.003)$ & $-0.21^{* *}(0.017)$ \\
Who initiated the CFI: Dummy (Villagers $=1)$ & $-19.73^{*}(0.076)$ & $0.09(0.370)$ \\
CFI formation period: Dummy (post 1995 $=1)$ & $150.82^{* *}(0.025)$ & $-1.09^{* *}(0.033)$ \\
Gini coefficient for land owned by villagers & $0.46(0.109)$ & $-0.004^{*}(0.052)$ \\
\% village households with migrant males & 7.66 & 0.55 \\
Constant & & \\
\hline
\end{tabular}

$\Omega$ Average proportion of EC women per meeting. OLS $(r)=$ regression with robust standard errors.

Numbers in parentheses are $p$-values. Significance: ${ }^{* * *}$ at $1 \%,{ }^{* *}$ at $5 \%,{ }^{*}$ at $10 \%,{ }^{\dagger}$ at close to $10 \%$.

The difference between the coefficients of GenComp 3 and Gencomp4 (the gender composition intervals.

$\geqslant 25-<33 \%$ and $\geqslant 33 \%$ ) is not significant even at $10 \%$ in Eqn. (1), but it is significant at $5 \%$ in Eqn. (2). 
Table 6. Nepal: factors affecting women's attendance in EC meetings

\begin{tabular}{lcc}
\hline & \multicolumn{2}{c}{ Dependent variables } \\
\cline { 2 - 3 } & Percent meetings with no EC women & Female attendance rate \\
\hline Statistical method & OLS $(r)$ & $(1)$ \\
Equation no. & 34 & $(2)$ \\
No. of observations & 0.67 & 34 \\
$R^{2}$ & Coef. & 0.38 \\
Explanatory variables & $-36.93^{* * *}(0.000)$ & $0.23^{*}(0.062)$ \\
\hline GenComp3: Dummy $(\geqslant 25-<33 \%$ EC women $=1)$ & $-36.53^{* * *}(0.000)$ & $0.20^{*}(0.055)$ \\
GenComp4: Dummy $(\geqslant 33 \%$ EC women $=1)$ & $-0.97^{*}(0.079)$ & $0.014^{*}(0.083)$ \\
Average age of EC members & $11.91^{* *}(0.049)$ & $-0.11(0.166)$ \\
Who made forest use rules: Dummy (without FD help $=1)$ & $-0.04(0.788)$ & $-0.004(0.182)$ \\
\% member households with migrant males & $-11.28^{*}(0.063)$ & $0.19^{*}(0.055)$ \\
Firewood shortage: Dummy (If shortage $=1)$ & 86.97 & -0.20 \\
Constant & & \\
\hline
\end{tabular}

$\Omega$ Average proportion of EC women per meeting. OLS $(r)=$ regression with robust standard errors.

Numbers in parentheses are $p$-values. Significance: ${ }^{* * *}$ at $1 \%,{ }^{* *}$ at $5 \%,{ }^{*}$ at $10 \%$.

The difference between the coefficients of GenComp3 and Gencomp4 (the gender composition intervals $\geqslant 25-<33 \%$ and $\geqslant 33 \%$ ) is not significant at $10 \%$ in either equation.

Table 7. Gujarat: factors affecting women speaking up in EC meetings

\begin{tabular}{|c|c|c|c|c|}
\hline & \multicolumn{4}{|c|}{ Dependent variable: do women speak up in EC meetings: Dummy ${ }^{\mathrm{a}}$} \\
\hline Statistical method & & \multicolumn{2}{|c|}{ Logit } \\
\hline Equation no. & \multicolumn{2}{|c|}{ (1) } & \multicolumn{2}{|c|}{$(2)$} \\
\hline No. of observations & \multicolumn{2}{|c|}{34} & \multicolumn{2}{|c|}{35} \\
\hline Explanatory variables & Coef. & M.E. & Coef. & M.E. \\
\hline GenComp1: \% EC women & $0.35^{* *}(0.016)$ & $0.05^{* *}(0.013)$ & & \\
\hline$\%$ EC women from landless households & $0.06^{* *}(0.020)$ & $0.01^{* *}(0.033)$ & $0.05(0.151)$ & $0.01^{*}(0.094)$ \\
\hline$\%$ illiterate EC women & $0.006(0.785)$ & $0.001(0.786)$ & $0.011(0.522)$ & $0.002(0.527)$ \\
\hline Protection method: Dummy (Guard $=1$; Patrol or informal lookout $=0$ ) & $5.27^{* *}(0.030)$ & $0.59^{* * *}(0.001)$ & $2.75^{* *}(0.037)$ & $0.42^{* *}(0.010)$ \\
\hline District2: Dummy (Panchmahals $=1)$ & $-5.31^{* *}(0.037)$ & $-0.77^{* * * *}(0.001)$ & $-5.04(0.128)$ & $-0.81^{* * *}(0.002)$ \\
\hline District3: Dummy (Sabarkantha $=1)$ & $-5.08^{*}(0.076)$ & $-0.82^{* * *}(0.001)$ & $-1.94(0.303)$ & $-0.40(0.288)$ \\
\hline Firewood shortage: Dummy (If shortage $=1$ ) & $3.45^{*}(0.086)$ & $0.67^{* *}(0.022)$ & & \\
\hline
\end{tabular}

Numbers in parentheses are $p$-values. Significance: ${ }^{* * *}$ at $1 \%,{ }^{* *}$ at $5 \%,{ }^{*}$ at $10 \%$.

M.E., marginal effect. The ME is for a discrete change from 0 to 1 for dummy variables, and for a one unit change for continuous variables.

In Eqn. (2), the difference between the coefficients of GenComp3 and Gencomp4 (the gender composition intervals $\geqslant 25-<33 \%$ and $\geqslant 33 \%$ ) is significant at $10 \%$.

Difference in models: In Eqn. (1), gender composition is a continuous variable. In Eqn. (2) gender composition is constituted into interval dummies; also firewood shortage was omitted from Eqn. (2) due to hidden collinearity (see also Footnote 27).

${ }^{a}$ If some or most women spoke up in any one of the last $3 \mathrm{EC}$ meetings $=1$; If none spoke up $=0$.

${ }^{\mathrm{b}}$ Reference category GenComp2: Dummy $(<25 \%$ EC women).

area owned by EC members (Table 5, Eqn. (2)). ${ }^{22}$ Landless women tend to attend because of the acute problems they face with forest closure (such as firewood shortages) and despite their time constraints from wage work, or the absence of male members due to out-migration. Women from households with more land tend to attend because they are somewhat less time constrained than landless women, and although they may be less forest dependent their interest in firewood and fodder availability is still strong. ${ }^{23}$ In other words, for somewhat differing reasons, women from both ends of the spectrum of land ownership tend to attend meetings.

In Nepal, as noted, there is very little representation of the landless in the EC for this variable to make an impact. Nevertheless, the Nepal results demonstrate in a different way that women's special interests can compel them to turn up for meetings: for instance, they are more likely to attend where there are firewood shortages (by both attendance indicators:
Table 6, Eqns. (1) and (2)). Firewood - a daily need-is collected almost entirely by women and girls and access to it has been restricted by forest closures. By attending meetings, EC women get a chance to raise this issue of critical importance to themselves and to their constituencies. Indeed, that a higher percentage of landless women in the EC or the experience of firewood shortages are both significant (the former in Gujarat the latter in Nepal) indicates that high dependence on the forest is an important factor encouraging women to attend meetings, despite restrictive social norms and time constraints. Firewood shortages, as we will see below, are also significant in explaining whether women will speak up at meetings in Gujarat, although they were not found significant in explaining attendance in Gujarat (the latter results are not presented here).

Second, ECs with a higher average age are found more likely to attend in Nepal. Older people tend to have more time to 
Table 8. Nepal: factors affecting women speaking up in EC meetings

\begin{tabular}{|c|c|c|c|c|}
\hline \multirow{5}{*}{$\begin{array}{l}\text { Statistical method } \\
\text { Equation no. } \\
\text { No. of observations } \\
\text { Pseudo } R^{2} \\
\text { Explanatory variables }\end{array}$} & \multicolumn{4}{|c|}{ Dependent variable: do women speak up in EC meetings: Dummy ${ }^{\mathrm{a}}$} \\
\hline & \multirow{3}{*}{\multicolumn{2}{|c|}{$\begin{array}{c}\text { Logit } \\
(1) \\
34 \\
0.34\end{array}$}} & \multirow{3}{*}{\multicolumn{2}{|c|}{$\begin{array}{c}\text { Logit } \\
(2) \\
34 \\
0.34\end{array}$}} \\
\hline & & & & \\
\hline & & & & \\
\hline & Coef. & M.E. & Coef. & M.E. \\
\hline GenComp1: \% EC women & $0.08^{*}(0.077)$ & $0.01^{* *}(0.046)$ & & \\
\hline$\%$ illiterate EC women & $0.004(0.755)$ & $0.000(0.752)$ & $0.008(0.571)$ & $0.001(0.559)$ \\
\hline $80 \%$ single caste: Dummy $(>80 \%$ EC members from single caste $=1)$ & $1.38(0.181)$ & $0.16(0.259)$ & $1.70(0.114)$ & $0.20(0.173)$ \\
\hline Who made forest use rules: Dummy (without FD help $=1$ ) & $1.57(0.262)$ & $0.15(0.274)$ & $1.58(0.260)$ & $0.14(0.278)$ \\
\hline District: Dummy $($ Baglung/Parbat $=1)$ & $2.33^{\dagger}(0.105)$ & $0.29(0.143)$ & $2.16^{\dagger}(0.101)$ & $0.25(0.139)$ \\
\hline Firewood shortage: Dummy (If shortage $=1$ ) & $1.50(0.180)$ & $0.18(0.210)$ & $1.98(0.201)$ & $0.24(0.238)$ \\
\hline Constant & -4.57 & & -4.15 & \\
\hline
\end{tabular}

Numbers in parentheses are $p$-values. Significance: ${ }^{* *}$ at $5 \%,{ }^{*}$ at $10 \%,{ }^{\dagger}$ at close to $10 \%$.

M.E., marginal effect. The ME is for a discrete change from 0 to 1 for dummy variables, and for a one unit change for continuous variables.

In Eqn. (2), the difference between gender composition intervals $\geqslant 25-<33 \%$ and $\geqslant 33 \%$ (GenComp3 and Gencomp4) is significant at $10 \%$.

Difference in models: In Eqn. (1), gender composition is a continuous variable. In Eqn. (2) gender composition is constituted into interval dummies.

${ }^{\mathrm{a}}$ If most or some women spoke up in any one of the last $3 \mathrm{EC}$ meetings $=1$; If none spoke up $=0$.

${ }^{\mathrm{b}}$ Reference category GenComp2: Dummy $(<25 \%$ EC women).

Table 9. Nepal: factors affecting women holding office

\begin{tabular}{|c|c|c|}
\hline & \multicolumn{2}{|c|}{ Dependent variables } \\
\hline & $\begin{array}{l}\% \text { women EC members } \\
\text { who are office bearers }\end{array}$ & Gender gap in office bearing ${ }^{a}$ \\
\hline Equation no. & (1) & $(2)$ \\
\hline No. of observations & 38 & 38 \\
\hline$R^{2}$ & 0.47 & 0.49 \\
\hline GenComp4: Dummy $(\geqslant 33 \% \text { EC women }=1)^{\mathrm{b}}$ & $27.94^{* * *}(0.000)$ & $-38.51^{* * *}(0.000)$ \\
\hline$\%$ female EC who are illiterate & $-0.08(0.169)$ & \\
\hline Gender gap in illiteracy (\% illiterate female EC - \% illiterate male EC) & & $0.18^{*}(0.061)$ \\
\hline Who made forest use rules? Dummy (without FD help = 1) & $-2.67(0.574)$ & $14.09^{*}(0.061)$ \\
\hline No. of toles in CFI & $2.09^{*}(0.065)$ & $-3.89^{* *}(0.035)$ \\
\hline CFI formation period: Dummy (Post-1996 = 1) & $1.62(0.669)$ & $-4.73(0.449)$ \\
\hline
\end{tabular}

Numbers in parentheses are $p$-values. Significance: ${ }^{* * *}$ at $1 \%,{ }^{* *}$ at $5 \%,{ }^{*}$ at $10 \%$.

$\mathrm{OLS}(r)=$ regression with robust standard errors.

The difference between the coefficients of GenComp3 and Gencomp4 (the gender composition intervals $\geqslant 25-<33 \%$ and $\geqslant 33 \%$ ) is significant at $5 \%$ in both equations.

${ }^{a}$ Gender gap in office bearing: \% male office bearers minus \% female office bearers at the time of the survey.

${ }^{\mathrm{b}}$ Reference category GenComp2: Dummy ( $<25 \%$ EC women).

attend, and older women in particular are usually relieved of some of their household tasks by daughters-in-law. A woman EC member expressed this graphically:

My workload has decreased at home because I have a daughter-in-law now and my daughter has also grown up. But since the Mandali started I am very busy attending meetings, attending workshops, going to training programs! (woman EC member, Sabarkantha district, Gujarat, author's survey, 2000).

Third, women are found more likely to attend meetings where the Forest department (FD) or an NGO has catalyzed the CFI or helped in the framing of its forest use rules. Especially in Gujarat, as a result of pressure from women's organizations and gender specialists in recent years, civil society organizations as well as government officials have begun to place emphasis on women's presence in public decision mak- ing, influenced too by gender quotas in village councils. Hence they often tend to be more gender progressive than traditional village leaders. A related, significant factor in Gujarat is the date of CFI formation. Women are more likely to attend meetings among CFIs formed after 1995 (Table 5: Eqn. (1)) when, as noted, local NGOs took measures to increase the gender sensitivity of their staff and of the villagers. ${ }^{24}$

Fourth, locational economic factors matter in both regions. In Gujarat, the higher the economic inequality in village land ownership, the poorer the attendance by both attendance indicators. Also the higher the percentage of village households which have migrant male members, the more likely are women to be absent from meetings (the coefficient is significant in Gujarat but not in Nepal). Overall, village economic inequality, as reflected in various indices (among which the results show a consistency), tends to reduce women's participation 
in meetings, but this negative effect can partly be overcome by inducting landless women directly into the EC-women who, as noted, have a particular stake in attending meetings.

Much of this is as hypothesized. However, some factors which can influence women's attendance are difficult to capture statistically, in particular the timing of meetings and women's responsibility for childcare, housework, and cattle care - in a large number of CFIs women mention these as constraints.

We want to attend meetings, but it is difficult when you have the responsibility of the house, the field, the children, the cattle. We can manage a limited number of things in a day (EC woman in a Narmada CFI, Gujarat, author's survey, 2000-01).

For me, either my husband should be at home or someone should help with my housework. Otherwise, I cannot attend the meetings regularly (EC woman in a Gorkha CFI, Nepal, author's survey, 2000-01).

The timing of EC meetings is context-specific and amicable to change if the CFI so decides, but the gender division of labor tends to be more inflexible. ${ }^{25}$

\section{(ii) Speaking up at meetings}

Men don't stop us from speaking, but they do all the talking (EC women in Narmada district, Gujarat, author's survey, 2000-01)

Men do not listen to us.....Therefore, if there is a majority of women, we will feel more confident in speaking up (EC women in a Baglung CFI, Nepal, author's survey, 2000-01)

Speaking up, as discussed above, is a much more complex behavioral issue than simply attending meetings. In principle, each EC woman may be expected to attend a meeting, but not each woman who attends may be expected to speak. Speaking up, even if there are no social constraints, can depend on the dynamics of the meeting-for instance, whether a particular woman speaks can depend on whether the point she wants to make has already been made by someone else or warrants repetition. Nevertheless there is an aspect of speaking up which can depend on the presence of other women, namely, in helping village women overcome their shyness and diffidence. Hence we would expect at least some women to speak up if there are more women around to support them. Even the mere presence of other women can help make the public space less male dominated and provide women the silent strength of numbers. In the equations, I base my interpretations on the significance of the marginal effect, even if the coefficient of the variable is not significant.

In both Gujarat and Nepal, the EC's gender composition is found to be important in determining whether at least some women express themselves in meetings (Tables 7 and 8). The greater the percentage of women on the EC the more likely that some or most women will speak up. In Gujarat, for example, the marginal effect for gender composition indicates that the probability of women speaking up is 5\% higher for every 1 point increase in the percentage of women on the EC (Table 7, Eqn. (1)). Further, the probability of at least some women speaking up is $48 \%$ greater among ECs with $\geqslant 33 \%$ women compared to those with $<25 \%$ women and also significantly greater compared to ECs with $\geqslant 25-<33 \%$ women (Table 7, Eqn. (2)). For Nepal, the probability of at least some women speaking up is $27 \%$ higher in a similar comparison of ECs with $\geqslant 33 \%$ women with those with $<25 \%$ women (Table 8 , Eqn. (2)). These do not translate into threshold effects since we are not measuring the likelihood of each woman speaking up. Indeed, as noted, it is unlikely that every woman will speak at a meeting even when able to. What the results do illustrate, however, is that with more women at least some women will tend to speak up. In this sense this is similar to the "no woman attending" variable, in that greater numbers can lead to at least some women attending a meeting.

EC women themselves consistently maintain - in $78 \%$ of the CFIs in Gujarat and $85 \%$ in Nepal- that the presence of other women helps greatly in enabling them to voice their views, in the encouragement, support, and self-confidence this provides. ${ }^{26}$ The following responses are typical:

If there is only one woman attending the meeting then she might find it hard to speak. But if there is a group of us then there is no problem (EC woman in a Sabarkantha CFI, Gujarat, author's survey, 2000$01)$

It helps to have more women because then women will not be dominated or feel shy. After all, if there is only one woman and ten men, how will she speak? Women need each other to be able to speak up (village woman in a Panchmahals CFI, Gujarat, author's survey, 2000-01).

Another notable factor observable from the Gujarat results is the effect of special interests in inducing women to speak up: there is a $67 \%$ greater probability of women speaking up at meetings where the village has reported firewood shortages than where there are no reported shortages (Table 7, Eqn. (1)). ${ }^{27}$ Firewood shortages affect both poor and well-off women in an everyday sense, providing them an incentive to attend. But over and above this, women are found more likely to speak up in ECs with more landless women (the marginal effect is significant though small). That landless women tend to attend and speak up at meetings is interesting but not surprising given their noted high dependence on the local forest and difficulties faced from forest closure. They therefore need to speak up to promote their interests, such as by pushing for more lenient forest use rules that allow some extraction of firewood where none is currently allowed, or that allow more extraction than is currently allowed. Overall it is notable that including more landless in the EC increases the likelihood not only of women attending meetings but also of their speaking up at them.

Another piece of this story lies in the finding, also from Gujarat, that where the CFI is protected by a guard rather than by a patrol group or other method, women tend to speak up more-there is a $59 \%$ higher probability of women speaking up in CFIs with a guard than if there is none (Table 7, Eqn. (1)). ${ }^{28}$ There appear to be at least two reasons for this. First, women, especially poor women, tend to get caught by the guards for stealing firewood, and altercations between local women and guards are more frequent than altercations with the village patrol. Guards, as noted, are often stricter than patrols, hold more formal authority and tend not to let intruders get away. EC meetings are an important forum for resolving such conflicts, and EC women are more compelled to speak up or be called upon to speak where such conflicts involve village women. Second, households contribute toward the upkeep of guards by paying cash or kind, and ensuring regular payments requires consensus among EC members, including women. One other factor warrants mention. Contrary to expectation, illiteracy among female EC members has virtually no effect on the likelihood of them speaking up in either Gujarat or Nepal.

\section{(iii) Women as office bearers}

The third dimension of women's effective participation is holding office. For Nepal, where one or more women held office in $42 \%$ of the mixed CFIs, we can explore whether women are more likely to do so in ECs with more female members, and also whether such ECs tend to have a lower gender gap 
in office bearing. We find that the percentage of EC women becoming office bearers is indeed higher if they belong to ECs with $\geqslant 33 \%$ women in comparison to those with $<25 \%$ women as well as those with $\geqslant 25-<33 \%$ women (Table 9, Eqn. (1)). There is a 28-point difference between ECs with less than a quarter women and those with one-third or more women in the percentage of EC women holding office. EC's with one-third or more women are also linked with a significantly lower gender gap in office bearing. However, ECs where illiteracy among female EC members is higher than men's have a higher gender gap in office bearing (Table 9, Eqn. (2)).

Of course being an office bearer does not automatically give the woman influence over decisions, but since appointing women to office is not mandatory in Nepal it is unlikely that most of them are merely figureheads, although some may be. A few whom I interviewed were articulate and active and some had influenced the decisions made. Studies of India's village councils are also indicative and present a mixed picture, with some council heads (pradhans) being figureheads and others being active. Women office bearers can, however, affect outcomes. For instance, in a study of two Indian states women pradhans were found to prioritize different public goods than male pradhans (Chattopadhyay \& Dufflo, 2004), and although the performance of first-time pradhans tended to be underrated by the villagers due to a negative perception bias about women, the bias declined with second-time pradhans, suggesting that greater exposure to women leaders can help (Beaman, Chattopadhyay, Dufflo, Pande, \& Tapolva, 2008).

\section{(iv) Further discussion}

Direct observation by me and my field staff of the dynamics of 17 EC meetings in as many sample villages, during a followup exercise in Gujarat, reinforced many of the above conclusions, and also provided additional insights. Three features of these meetings were striking. First it was indeed the case that where there are several women in the EC, at least some turn up for meetings, and where many turn up they tend to be more vocal. If there are only two or less women they feel intimidated. However, albeit unusually, an older articulate woman who has leadership qualities can speak up and persuade the men even in ECs with low female presence; in such cases other women might simply nod without saying anything themselves. Second, a dominant male President can silence women even if they are one-third of the EC; indeed he can silence the men too, as I found in one Gujarat village where seating arrangements at the meetings replicated the typical pattern of men sitting on chairs or benches and women sitting on the floor on one side, with the President holding forth and dominating the decision-making process. Third, just as a dominant male President can silence women so a sympathetic one can empower them. In one village at an EC meeting two of the four women EC members made several interesting observations, but for these to affect the final decision the male President had to reinforce women's opinions. The issue under discussion was the location of a water trough for cattle that would cater to two hamlets. When no consensus seemed in sight, one of the women suggested that it be located in the middle of the two hamlets and near a well, so that both hamlets could use it and filling it would also be easier. Some men objected saying: "We can't accept what you are suggesting simply because you are saying so," but the President pointed out that it was the most reasonable solution, to which everyone then agreed. Such gender-sensitive male Presidents are, however, rare.

Nevertheless, over time, it is not unlikely that as women's presence in CFI decision making becomes more commonplace, negative male attitudes and social norms will also change (as observed for women pradhans). Here again women's greater numbers in CFIs can help. Also, prior group activity by village women, even if unrelated to forestry, could enhance female presence, attendance and speaking up in CFIs, due to the experience women gain through such activity.

\section{CONCLUDING COMMENTS}

Women's proportional strength in the EC is found consistently important in enhancing women's participation in governance, not just nominally but effectively. For a start, the more women there are on the EC the greater the likelihood of women attending EC meetings, speaking up at them, and being office bearers. Having more women ensures that there is at least some female presence in most meetings. The attendance rate also improves and there is evidence of a critical mass effect. Women's attendance rate is significantly higher in CFIs where 25 to $33 \%$ of the EC consists of women compared with ECs with less than $25 \%$ women. The likelihood of at least some women speaking up, however, becomes significantly greater at a somewhat higher level of women's presence, namely among ECs with a third or more women members.

One-third has become the popularly accepted cut-off point (largely without empirical verification) in arguments for women's presence, on the assumption that this is necessary for women's effectiveness in Parliament or other public bodies such as village councils. The discussion on critical mass in this literature has focused almost entirely on the impact of women's presence on decisions made, rather than on the process of decision making. My results support the idea that a critical mass is important even for the process, in relation to women attending meetings. Although this critical mass lies in a somewhat wider range than simply one-third-namely, between a quarter and a third - the range is fairly close to the popularly emphasized percentage. The paper thus provides notable empirical support for the popular view and strengthens the policy argument for promoting at least these proportions of women in decision-making bodies.

The presence of more women on the EC, however, is not sufficient for ensuring that women become office bearers. A mandate for including a certain percentage of women as office bearers and leadership training for them may be necessary to break the glass ceiling effect. In Gujarat, for instance, this barrier was broken where some of the women who had received leadership training became EC presidents or vice-presidents. Such training can enhance women's capabilities and also signal to the community that women too should hold office. In Nepal this message was conveyed by demonstration through the gender-inclusive nature of FECOFUN's Constitution. Such a message, however, simply lays the ground for inducting women into office, it does not guarantee it. The geographic location of the Nepal sites where social norms are less restricted for women, even among the upper-castes, is also clearly important, although here too measures to enhance women's self-confidence and experience of public forums can help, as recent donor attempts demonstrate (LFP, 2007).

It is notable that where women have a personal stake in the outcomes of meetings (e.g., if they are experiencing firewood shortages or persistent conflicts with guards) they are more likely to attend meetings and/or speak up at them. It would be interesting to test this in other institutional contexts as well. Women's class position also matters but not in the expected way. The finding that ECs with a higher percentage of landless women have greater female attendance and voice indicates that being poor and female does not necessarily confine a 
person to the bottom of the pyramid. Landless women are less constrained by social norms and status considerations, and have more stake in forest access, compelling them to attend and speak up. This also alerts us to the importance of including disadvantaged women, and not simply any women, in community institutions of governance.

There is a view within the feminist debate that economic and social inequalities can obstruct women's participation in public discussion. Some scholars, in fact, see relative socio-economic equality as a necessary condition for people to participate, among them being Fraser (1990, p. 65), who notes: "It is a necessary condition for participatory parity that systematic social inequalities be eliminated." However, my results (and personal observation of grassroots women's meetings in
South Asian villages), suggest that prior equality is not necessary for women to assert themselves. In fact, women from disadvantaged households, especially if present in sufficient numbers or with prior exposure to women's empowerment programs, can be more outspoken in public forums than women from well-off households, since they have less to lose by way of social status, and much to gain if the decisions go in their favor.

The impact of women's presence is thus mediated by a number of factors, including the individual attributes and skills of those composing the EC. This cannot always be captured statistically but it does suggest that while women's greater presence on the EC is critical, there are also aspects beyond mere numbers that would help make that presence effective.

\section{NOTES}

1. The terms threshold effect and critical mass are used interchangeably in the paper.

2. On critical mass see, among others, Kanter (1977a,1977b), Agarwal (1997,2001), Bratton (2005), Bratton and Ray (2002), Carroll and Taylor (1989), Dahlerup (1988), Lovenduski (1997), Saint-Germain (1989), Studlar and McAllister (2002), Swers (2001), Thomas (1994), and Wängnerud (2000).

3. Among these few are Bratton and Ray (2002) and Studlar and McAllister (2002). The latter find no critical mass effect. In some studies data constraints limit empirical testing: for example, Thomas (1994:101) found no US legislature with over $31 \%$ women and so could not test the potential impact of higher levels of women's presence. Studlar and McAllister (2002) could undertake such tests using cross-country data.

4. Most Latin American countries with political party quotas specify 30 $35 \%$ (Htun, 2002). India and Pakistan reserve one-third seats for women in village councils. Women's groups in many countries are also demanding one-third (see e.g., Norris \& Inglehart, 2001; Stevenson, 1999; and www.sardc.net/widsaa/sgm/1999/sgm_ch3.html).

5. See, as a sample (the list is illustrative, not comprehensive), Ahmed (1994), Bingeman (2001), Britt (1993), Buchy and Subba (2003), Correa (1997), Dahal (1994), Davidson-Hunt (1995), Ghimire-Bastakoti and Bastakoti (2006), Guhathakurta and Bhatia (1992), Gururani (1996), Hobley (1990), Hobley (1996), ISO/Swedforest. (1993), Kant, Singh, and Singh (1991), Lama and Buchy (2002), Mansingh (1991), Moffatt (1998), Mukerjee and Roy (1993), Pandey (1990), Raju (1997), Roy, Mukerjee, and Chatterjee (1992), Roy, Mukerjee, Roy, Bhattacharya, and Bhadra (1993), Sarin (1995), Sarin (1998), Sarin and Khanna (1993), Seeley (1996), Shah and Shah (1995), Sharma and Sinha (1993), Singh (2001), Singh and Kumar (1993), TERI (1995), Viegas and Menon (1993), and Venkateshw$\operatorname{aran}(1992)$.

6. For instance, Agrawal and Chhatre (2006) test how "gender conflict" and "gender relations" in the village affect forest condition in Himachal Pradesh (India), although neither gender variable (as defined by the authors) is related to institutions of forest governance. Prokopy (2004), likewise, although in the context of water management, examines the effect of women's presence in water users' committees on project outcomes. She also measures women's attendance at committee meetings but not whether women's numbers affect that attendance. Beyond South Asia and unlinked to natural resource issues, similarly, the focus is mainly on project performance: for example, Molinas (1998) tests the effect of women's membership in Paraguay's farmers' cooperatives on cooperative perfor- mance. Elsewhere, I too have examined in depth the impact of women's presence in forest governance on outcomes, such as on forest use rules and forest condition (Agarwal, 2009, in press-a,b).

7. There is a vast body of work on community forestry in India and Nepal-its origins, functioning and performance, and differences therein - which it is not possible to reference here, but see among others Agarwal (2001, 2006, in press-b), Jeffery and Sundar (1999), Poffenberger and McGean (1996), Hobley (1996), Springate-Baginski and Blaikie (2007), and references therein.

8. For India see Bahuguna (2004) and for Nepal see (GoN 2000).

9. Figures for the early 1990 s are indicative. In rural India, $80 \%$ of the households using firewood as cooking fuel gathered it from forests, village commons and private sources (NCAER 2000-01). Similarly, in rural Nepal, $82 \%$ of the households using firewood as their primary cooking fuel gathered it (Loughran \& Pritchett, 1997).

10. Gujarat is larger in geographic area and population size than Nepal as a whole.

11. Earlier Narmada district was a part of Bharuch district, and the sample CFIs fall mainly in Narmada with some spillover into present-day Bharuch

12. Four of the originally-selected Gorkha CFIs became inaccessible due to the Maoist insurgency. These were replaced by CFIs with the same gender composition from a contiguous part of the adjacent Dhading district.

13. See Acharya and Bennett (1983) for the 1980s and Bennett and Gajurel (2006) for a recent picture.

14. The members of CFIs with all-women ECs can be both men and women, as is the case with other CFIs. It is only the management unit that is all-women.

15. Baglung and Parbat are contiguous districts with a similar ecological and social profile. But each had only 14 all-women CFIs, which was insufficient to take each district on its own. The two districts were thus clubbed for sample selection. Gorkha with 42 all-women groups was treated as a separate unit.

16. In the Gujarat sample there were three all-women and five all-men CFIs. In the Nepal sample, there were 27 all-women and five all-men CFIs. 
17. The information was obtained through a team of six researchers (all with university degrees) from Nepal and six from Gujarat who knew the local dialect. They traveled in teams of two-typically a man and a woman. Each team spent on average $3 \frac{1}{2}$ days in the field for every CFI. In Nepal, given the physical remoteness of many villages and the ongoing Maoist insurgency, the researchers often stayed in the village itself. This involved hardship but also helped build rapport with the informants. In both Gujarat and Nepal, most and sometimes all of the EC members were present for discussions on the EC-related questionnaire, and a fairly wide cross-section of people were present for the focused group discussions with villagers/forest users. Where possible, separate discussions were also held with low-caste communities living at a distance. In individual interviews the key informants were former EC members (one man and one woman from different households in each CFI), and sometimes (additionally) elderly villagers and forest guards.

18. For information on population by gender, land owned by each household, and migrant males, a village census was undertaken for all the 65 Gujarat villages.

19. For further details on the data and how they were collected see Agarwal (in press-b).

20. For CFIs which lacked such records it is not possible to tell whether the meeting was not held at all, or was held but not recorded.

21. The experimental games literature indicates similar gender patterns. Sell (1997), for instance, using US undergraduates as subjects, finds that women cooperate more in all-women groups since they feel more empowered there than as minorities in a mixed-gender group, while men cooperate more in predominantly female groups in which they expect to carry more influence than in all-male groups.
22. There is a high correlation (0.81) between average land owned by all EC households and average land owned by female EC households in Gujarat. I used the former as a proxy since the latter was also highly correlated with the percentage of landless women in the EC.

23. Indeed, landed households would tend to have more livestock and so would have more interest than the landless in access to fodder, even if they can draw on private resources for a part of their needs.

24. I did not include this variable for Nepal since there was no such datespecific input here; the formation of FECOFUN is relevant mainly for office bearing where the date of formation is used as an explanatory variable.

25. For a more wide-ranging discussion on the constraints rural women across India and Nepal face in participating in CFIs, see Agarwal (2001).

26. As noted, Thomas (1994) observed something similar in a very different cultural context.

27. Firewood shortage was not used as an explanatory variable in Gujarat's Eqn. (2) of speaking up due to problems of "hidden collinearity." This can occur, for instance, in logit analysis when several explanatory variables are dummies, leading to missing standard errors for one or more of the estimated coefficients. The solution is usually to drop the variable due to which this occurs.

28. This could only be tested for Gujarat. In Nepal, the inclusion of protection method as an explanatory variable in the speaking up equations caused problems of "hidden collinearity."

\section{REFERENCES}

Acharya, M., \& Bennett, L. (1983). Women and the subsistence sector: Economic participation and household decentralization in Nepal. World Bank Staff Working Paper No. 526. World Bank, Washington DC.

Ahmed, S. (1994). The rhetoric and reality of women's participation in Joint Forest Management: The case of an NGO in western India. Paper presented for an international seminar on women, poverty and demographic change, Oaxaca, Mexico, October.

Agarwal, B. (1997). Environmental action, gender equity, and women' participation. Development and Change, 28(1), 1-44.

Agarwal, B. (2000). Conceptualizing environmental collective action: Why gender matters. Cambridge Journal of Economics, 24(3), 283-310.

Agarwal, B. (2001). Participatory exclusions, community forestry and gender: An analysis and conceptual framework. World Development, 29(10), 1623-1648.

Agarwal, B. (2006). Gender inequality, cooperation and environmental sustainability. In J.-M. Baland, S. Bowles, \& P. Bardhan (Eds.), Inequality, cooperation, and environmental sustainability (pp. 274-313). Princeton: Princeton University Press.

Agarwal, B. (in press-a). Gender and forest conservation: The impact of women's participation in community forest governance. Ecological Economics.

Agarwal, B. (in press-b). Gender and Green governance: The political economy of women's presence in community forestry and beyond. Oxford: Oxford University Press.

Agarwal, B. (2009). Rule making in community forestry institutions: The difference women make. Ecological Economics, 68, 2296-2308.

Agrawal, A., \& Chhatre, A. (2006). A forest governance in the Indian Himalaya. World Development, 34(1), 149-166.

Beaman, L. Chattopadhyay, R. Dufflo, E., Pande, R., \& Tapolva, P. (2008). Powerful women: Does exposure reduce bias? Working paper RWP08037, John F. Kennedy School of Government, Harvard University.

Bahuguna, V. K. (2004). Root to canopy: An overview. In V. K. Bahuguna, K. Mitra, D. Capistrano, \& S. Saigal (Eds.), Root to canopy (pp. 15-24). New Delhi: Commonwealth Forestry Association and Winrock International.
Bennett, L., \& Gajurel, K. (2006). Negotiating social change: Gender, caste and ethnic dimensions of empowerment and social inclusion in rural Nepal. In R. Alsop, M. Bertelsen, \& J. Holland (Eds.), Empowerment in practice. From analysis to implementation (pp. 192-217). Washington, DC: The World Bank.

Bingeman, K. (2001). Policy, gender and institutions: A journey though forest management issues in the Kullu Valley, Himachal Pradesh, India. Masters thesis in Natural Resource Management, University of Manitoba, Winnipeg.

Bratton, K. A. (2005). Critical mass theory revisited: The behavior and success of token women in state legislatures. Politics \& Gender, 1(1), 97-125.

Bratton, K. A., \& Ray, L. P. (2002). Descriptive representation, policy outcomes, and municipal day-care coverage in Norway. American Journal of Political Science, 46(2), 428-437.

Britt, C. (1993). Out of the wood? Local institutions and community forest management in two central Himalayan villages. Ithaca: Cornell University (draft monograph).

Buchy, M., \& Subba, S. (2003). Why is community forestry a social- and gender-blind technology? The case of Nepal. Gender, Technology and Development, 7(3), 313-332.

Correa, M. (1997). Gender and joint forest planning and management: A research study in Uttara Kannada District. Karnataka, Dharwad: India Development Service.

Carroll, S. J., \& Taylor, E. (1989). Gender differences in policy priorities of US state legislators. Paper presented at the American Political Science Association, Atlanta.

Chattopadhyay, R., \& Dufflo, E. (2004). Women as policy makers: Evidence from an India-wide randomized policy experiment. Econometrica, 72(5), 1409-1444.

Dahal, D. R. (1994). A review of forest user groups: Case studies from eastern Nepal. Kathmandu: International Center for Integrated Mountain Development (ICIMOD).

Dahlerup, D. (1988). From a small to a large majority: Women in Scandinavian politics. Scandinavian Political Studies, 11(4), 275-298. 
Davidson-Hunt, K. (1995). Engendering the commons: A case study in gender, difference and common property in Himachal Pradesh. India. Masters thesis, Department of Anthropology, University of Manitoba, Winnipeg.

Fraser, N. (1990). Rethinking the public sphere: A contribution to the critique of actually existing democracy. Social Text, 25/26, 56-80.

Ghimire-Bastakoti, K., \& Bastakoti, R. R. (2006). Social exclusion in community forestry: Why women are frequently excluded from decision-making and leadership in Nepal. In Proceedings of the women's global connection conference on affirming diversity: Women making a difference, University of the Incarnate Word, San Antonio, TX, USA, May 18-20.

GoN. (2000). FUG database. Community and Private Forestry Division, Department of Forests, Government of Nepal, Kathmandu.

Guhathakurta, P., \& Bhatia, K. S. (1992). A case study on gender and forest resources in West Bengal. World Bank, Delhi, June 16.

Gururani, S. (1996). Fuel, fodder and forests: Politics of forest use and abuse in Uttarakhand Himalaya, India. Doctoral thesis in cultural anthropology, Syracuse University.

Hobley, M. (1990). Social reality, social forestry: The case of two Nepalese panchayats. Doctoral dissertation, Department of Forestry, Australian National University.

Hobley, M. (1996). Participatory forestry: The process of change in India and Nepal. London: Overseas Development Institute.

Htun, M. N. (2002). Women in political power in Latin America. International idea: Women in parliament. Stockholm, Sweden: $<$ http://www.idea.int $>$.

ISO/Swedforest (1993). Forests, people and protection: Case studies of voluntary forest protection by communities in Orissa. Delhi: Swedish International Development Agency (SIDA).

Jeffery, R., \& Sundar, N. (1999). A new moral economy for India's forests. New Delhi: Sage Publications.

Kant, S. N., Singh, M., \& Singh, K. K. (1991). Community-based forest management systems: Case studies from Orissa. New Delhi: SIDA; Bhopal: Indian Institute of Forest Management, and New Delhi: ISO/ Swedforest.

Kanter, R. M. (1977a). Men and women of the corporation. New York: Basic Books.

Kanter, R. M. (1977b). Some effects of proportions on group life: Skewed sex ratios and responses to token women. The American Journal of Sociology, 82(5), 965-990.

Kymilcka, W. (1995). Multicultural citizenship: A liberal theory of minority rights. Oxford: Clarendon Press.

Lama, A., \& Buchy, M. (2002). Gender, class, caste and participation: The case of community forestry in Nepal. Indian Journal of Gender Studies, $9(1), 27-41$

LFP (2007). LFP's animation and social mobilization. Kathmandu, Nepal: Livelihoods and Forestry Programme.

Loughran, D., \& Pritchett, L. (1997). Environmental scarcity, resource collection, and the demand for children in Nepal. Policy Research Working Paper. Washington, DC: World Bank.

Lovenduski, J. (1997). Gender politics: A breakthrough for women? Parliamentary Affairs, 50, 708-719.

Mansingh, O. (1991). Community organization and ecological restoration: An analysis of strategic options for NGOs in central Himalaya, with particular reference to the Community Forestry Programme of the NGO Chirag, MA dissertation in Rural Development, AFRAS, University of Sussex.

Moffatt, M. (1998). A gender analysis of community forestry and community leasehold forestry in Nepal with a macro-meso-micro framework. M.A. dissertation in Development Policy Analysis, Department of Economics and Social Studies, University of Manchester.

Molinas, J. (1998). The impact of inequality, gender, external assistance and social capital on local-level cooperation. World Development, 26(3), 413-431.

Mukerjee, R., \& Roy, S. B. (1993): Influence of social institutions on women's participation in JFM: A case study from Sarugarh, North Bengal. Working Paper No. 17, IBRAD, Calcutta.

NCAER (2000-01). Evaluation survey of the national programme on improved chulas. Report. Delhi: National Council for Applied Economic Research.

Norris, P., \& Inglehart, R. (2001). Cultural obstacles to equal representation. Journal of Democracy, 12(3), 126-140.

Ojha, H. R., \& Timsina, N. P. (2008). Community-based forest management programmes in Nepal: Lessons and policy implications. In H. R.
Ojha, N. P. Timsina, C. Kumar, \& M. R. Banjade (Eds.), Communities forests and governance. New Delhi: Adroit Publishers.

Pandey, S. (1990). Women in Hattidunde forest management in Dhading District, Nepal. MPE Series No. 9, ICIMOD, Kathmandu.

Poffenberger, M., \& McGean, B. (Eds.) (1996). Village voices forest choices: Joint Forest Management in India. Delhi: Oxford University Press.

Prokopy, L. S. (2004). Women's participation in rural water supply projects in India. Water Supply, 6, 103-116.

Raju, M. (1997). Seeking niches in forest canopy: An enquiry into women's participation. Report, Ford Foundation, New Delhi.

Roy, S. B., Mukerjee, R., \& Chatterjee, M. (1992). Endogenous development, gender role in participatory forest management. Calcutta: IBRAD.

Roy, S. B., Mukerjee, R., Roy, D. S., Bhattacharya, P., \& Bhadra, R. K. (1993). Profile of joint forest protection committee at Sarugarh Range, West Bengal. IBRAD Working Paper No. 16, Calcutta.

Saint-Germain, M. A. (1989). Does their difference make a difference? The impact of women on public policy in the Arizona legislature. Social Science Quarterly, 70(4), 956-968.

Sarin, M. (1995). Regenerating India's forests: Reconciling gender equity and Joint Forest Management. IDS Bulletin, 26(1), 83-91.

Sarin, M. (1998). Who is gaining? Who is losing? Gender and equality concerns in Joint Forest Management. New Delhi: Society for Promotion of Wasteland Development.

Sarin, M., \& Khanna, R. (1993). Women organize for wasteland development: A case study of SARTHI in Gujarat. In A. Singh, \& N. Burra (Eds.), Women and wasteland development in India (pp. 129-169). Delhi: Sage Publications.

Seeley, J. (1996). Who benefits from participatory forest management. Banko Janakari, 6(1), 38-39.

Sell, J. (1997). Gender, strategies and contributions to public goods. Social Psychology Quarterly, 60(3), 252-265.

Shah, M. K., \& Shah, P. (1995). Gender, environment and livelihood security: An alternative viewpoint from India. IDS Bulletin, 26(1), $75-82$.

Sharma, A., \& Sinha, A. (1993). A study of the common property resources in the project area of the central Himalaya rural action group. Report, Indian Institute of Forest Management, Bhopal, Madhya Pradesh.

Singh, N. (2001). Women and community forests in Orissa: Rights and management. Indian Journal of Gender Studies, 8(2), 257-269.

Singh, N., \& Kumar, K. (1993). Community initiatives to protect and manage forests in Balangir and Sambalpur Districts. Report, SIDA, New Delhi.

Springate-Baginski, O., \& Blaikie, P. (Eds.) (2007). Forests, people and power: The political ecology of reform in South Asia. London: Earthscan.

Stevenson, L. S. (1999). Gender politics in the Mexican democratization process. In J. Dominquez, \& A. Poire (Eds.), Toward Mexico's democratization. Parties, campaigns, elections and public opinion. New York: Routledge.

Studlar, D., \& McAllister, J. (2002). A comparative analysis of women's legislative representation. European Journal of Political Research, 41, 233-253.

Swers, M. (2001). Understanding the policy impact of electing women: Evidence from research on congress and state legislatures. Political Science and Politics, 34(2), 217-220.

TERI. (1995). Community participation in van panchayats of Kumaon region of Uttar Pradesh. Paper No.1, Part I, Tata Energy Research Institute, Delhi.

Thomas, S. (1994). How women legislate. Oxford: Oxford University Press.

Viegas, P., \& Menon, G. (1993). Bringing government and people together: Forest protection committees of West Bengal - role and participation of women. In A. Singh, \& N. Burra (Eds.), Women and wasteland development in India (pp. 171-210). New Delhi: Sage Publications.

Venkateshwaran, S. (1992). Living on the edge: Women, environment and development. New Delhi: Friedrich Ebert Stiftun.

Wängnerud, L. (2000). Testing the politics of presence. Women's representation in the Swedish Riksdag. Scandinavian Political Studies, 23(1), 67-91

\section{APPENDIX A}

See Tables A1 and A2. 
Table A1. Gujarat: definitions and descriptive statistics

\begin{tabular}{|c|c|c|c|c|c|}
\hline Variable name & $N$ & Mean & $C V$ & Min & $\operatorname{Max}$ \\
\hline \multicolumn{6}{|l|}{ Dependent variables } \\
\hline$\%$ EC meetings with no EC women in all years of CFI functioning & 32 & 29.1 & 1.24 & 0 & 100 \\
\hline Female attendance rate in all years of CFI functioning & 32 & 0.5 & 0.62 & 0 & 1 \\
\hline \multicolumn{6}{|l|}{ Explanatory variables } \\
\hline GenComp 1: \% women in EC & 57 & 25.9 & 0.38 & 9.1 & 54.5 \\
\hline GenComp3: Dummy $(\geqslant 25 \%-<33 \%$ EC women $=1)$ & 57 & 13 & - & 0 & 1 \\
\hline GenComp4: Dummy $(\geqslant 33 \%$ EC women $=1)$ & 57 & 16 & - & 0 & 1 \\
\hline Average land owned by EC members (ha) & 56 & 1.2 & 0.56 & 0.35 & 4.20 \\
\hline$\%$ EC women from landless hhs & 56 & 22.3 & 1.81 & 0 & 100 \\
\hline$\%$ illiterate EC women & 57 & 53.5 & 0.67 & 0 & 100 \\
\hline Who initiated the CFI: Dummy (villagers $=1$; forest department or $\mathrm{NGO}=0$ ) & 57 & 29 & - & 0 & 1 \\
\hline CFI formation period: Dummy (Post-1995 = 1) & 57 & 27 & - & 0 & 1 \\
\hline District2: Dummy (Panchmahals $=1$ ) & 57 & 21 & - & 0 & 1 \\
\hline District3: Dummy (Sabarkantha $=1$ ) & 57 & 25 & - & 0 & 1 \\
\hline Firewood shortage: Dummy (If some or most have shortage $=1 ;$ if none have shortage $=0$ ) & 54 & 41 & - & 0 & 1 \\
\hline
\end{tabular}

Notes: for the dummy variables the means give the number of positive values.

$C V$, coefficient of variation.

Table A2. Nepal: definitions and descriptive statistics

\begin{tabular}{|c|c|c|c|c|c|}
\hline Variable name & $N$ & Mean & $C V$ & Min & $\operatorname{Max}$ \\
\hline$\%$ EC meetings with no EC women in all years of CFI functioning & 38 & 18.6 & 1.42 & 0 & 100 \\
\hline Female attendance rate in all years of CFI functioning & 38 & 0.5 & 0.52 & 0 & 1 \\
\hline$\%$ EC women who are office bearers & 38 & 13.3 & 1.36 & 0 & 66.7 \\
\hline Gender gap in office bearing ( $\%$ male office bearers - $\%$ female office bearers) & 38 & 36.3 & 0.76 & -33.3 & 80 \\
\hline GenComp1: \% women in EC & 38 & 30.5 & 0.49 & 6.67 & 63.6 \\
\hline GenComp2: Dummy (<25\% EC women $=1)$ (reference category) & 38 & 13 & - & 0 & 1 \\
\hline GenComp3: Dummy $(\geqslant 25-<33 \%$ EC women $=1)$ & 38 & 9 & - & 0 & 1 \\
\hline GenComp4: Dummy $(\geqslant 33 \%$ EC women $=1)$ & 38 & 16 & - & 0 & 1 \\
\hline Average age of all EC members & 38 & 43.2 & 0.12 & 33.7 & 54.5 \\
\hline$\%$ illiterate EC women & 38 & 42.2 & 0.90 & 0 & 100 \\
\hline Firewood shortage: Dummy (If some or most have shortages $=1$; if none have shortages $=0$ ) & 34 & 21 & - & 0 & 1 \\
\hline$\%$ member households with migrant males & 38 & 18.5 & 0.76 & 0 & 66.7 \\
\hline No. of toles & 38 & 5.6 & 0.48 & 3 & 13 \\
\hline District: Dummy (Baglung/Parbat $=1$; Gorkha/Dhading $=0$ ) & 38 & 22 & - & 0 & 1 \\
\hline
\end{tabular}

Notes: for the dummy variables the means give the number of positive values.

FD, forest department. 